\title{
Article \\ Investigating Primary Cilia during Peripheral Nervous System Formation
}

\author{
Elkhan Yusifov, Alexandre Dumoulin (1) and Esther T. Stoeckli * \\ Department of Molecular Life Sciences and Neuroscience Center Zurich, University of Zurich, \\ Winterthurerstrasse 190, 8057 Zurich, Switzerland; elkhan.yusifov@uzh.ch (E.Y.); \\ alexandre.dumoulin@mls.uzh.ch (A.D.) \\ * Correspondence: esther.stoeckli@mls.uzh.ch; Tel.: +41-44-635-4840
}

check for updates

Citation: Yusifov, E.; Dumoulin, A.; Stoeckli, E.T. Investigating Primary Cilia during Peripheral Nervous System Formation. Int. J. Mol. Sci. 2021, 22, 3176. https://doi.org/ $10.3390 /$ ijms 22063176

Academic Editors: Lies De Groef and Lieve Moons

Received: 31 January 2021

Accepted: 16 March 2021

Published: 20 March 2021

Publisher's Note: MDPI stays neutral with regard to jurisdictional claims in published maps and institutional affiliations.

Copyright: (c) 2021 by the authors. Licensee MDPI, Basel, Switzerland. This article is an open access article distributed under the terms and conditions of the Creative Commons Attribution (CC BY) license (https:// creativecommons.org/licenses/by/ $4.0 /)$.

\begin{abstract}
The primary cilium plays a pivotal role during the embryonic development of vertebrates It acts as a somatic signaling hub for specific pathways, such as Sonic Hedgehog signaling. In humans, mutations in genes that cause dysregulation of ciliogenesis or ciliary function lead to severe developmental disorders called ciliopathies. Beyond its role in early morphogenesis, growing evidence points towards an essential function of the primary cilium in neural circuit formation in the central nervous system. However, very little is known about a potential role in the formation of the peripheral nervous system. Here, we investigate the presence of the primary cilium in neural crest cells and their derivatives in the trunk of developing chicken embryos in vivo. We found that neural crest cells, sensory neurons, and boundary cap cells all bear a primary cilium during key stages of early peripheral nervous system formation. Moreover, we describe differences in the ciliation of neuronal cultures of different populations from the peripheral and central nervous systems. Our results offer a framework for further in vivo and in vitro investigations on specific roles that the primary cilium might play during peripheral nervous system formation.
\end{abstract}

Keywords: primary cilium; ciliogenesis; neural circuit formation; neural crest cells; DRG; boundary cap cells; sympathetic ganglia; PNS

\section{Introduction}

The primary cilium is a tiny nonmotile organelle that can be seen on most vertebrate cells [1-3]. It was discovered by the Swiss neuroscientist Karl Wilhelm Zimmermann in 1898 [4]. After its discovery, the primary cilium was neglected for a century as an evolutionary rudiment. However, studies in the last two decades have characterized the primary cilium as a signaling hub involved in distinct signaling cascades, such as Sonic Hedgehog (Shh) [5,6], Wnt [7,8], PDGFR [9,10], mTOR [11], and other pathways. Subsequent studies have demonstrated that the primary cilium is involved in the differentiation, proliferation, survival, polarity, and migration of cells [12]. That is why defects in the genes responsible for primary cilium formation and function have been identified as the cause for a group of disorders gathered under the umbrella of ciliopathies [13,14]. Common features in ciliopathies include retinal degeneration, craniofacial defects, polydactyly, intellectual disability, situs inversus, and cystic kidneys. As suggested by the name, proteins involved in ciliopathies are located either inside or at the base of the primary cilium [15]. Mutations in the genes responsible for primary cilia formation cause defective ciliary function in nonmotile ciliopathies and, thus, trigger various developmental and degenerative phenotypes in different tissues such as kidney, retina, and brain [16,17]. Human patients with ciliopathies, such as Joubert syndrome, can show pronounced abnormalities in the formation of the central nervous system (CNS). Translating observations from humans into model organisms has helped characterize pathological processes related to the loss of functional primary cilia at different levels, such as neuronal differentiation, migration, and axon tract formation [18-20]. However, to date, the potential role that the primary 
cilium might play during the formation of the peripheral nervous system is still poorly characterized, although several studies have suggested such a role [21,22].

Neural crest cells (NCCs) of the trunk are multipotent cells that delaminate from the dorsal neural tube and migrate laterally and ventrally using distinct trajectories. When they reach their final destination, they differentiate into dorsal root ganglia (DRG) neurons, sympathetic ganglia (SG) neurons, boundary cap cells (BCCs), or glial cells $[23,24]$. Neural crest cell development is, therefore, a prerequisite in the formation of a fully functional peripheral nervous system (PNS). Each step in the development of NCCs-delamination, migration, and differentiation into their derivatives-is temporally and transcriptionally regulated.

To learn more about the possible role of primary cilia in PNS development, it is crucial to first investigate whether distinct NCC populations possess a primary cilium during key stages of development in vivo. We could assess and confirm the presence of a primary cilium in migrating NCCs and their derivatives, such as DRG neurons, SG neurons, and BCCs in vivo. This confirmed that the primary cilium might be engaged in the development of the PNS at multiple levels. Moreover, we also characterized the timing of ciliation in dissociated and explant cultures of PNS and CNS neurons. We found that dissociated DRG neurons did not recover their primary cilium, whereas other neuronal populations, such as commissural neurons and motoneurons, largely did, albeit with distinct timing. Furthermore, when cultured as explants, neurons did not lose primary cilia in culture. Taken together, these findings will be useful for scientists trying to decipher molecular mechanisms of PNS assembly and the primary cilium in vivo and in vitro.

\section{Results}

\subsection{Trunk Neural Crest Cells Bear a Primary Cilium during Their Early Migration}

NCCs delaminating from the lumbar neural tube start migrating in a dorsal-to-ventral direction around Hamburger and Hamilton stage 16 (HH16) in chicken embryos and will then settle at their final destination prior to differentiation (Figure 1A-C) $[25,26]$. Immunohistochemistry was used to visualize the migration of NCCs and to characterize whether NCCs possess a primary cilium during their migration and early settlement in vivo. We stained transverse spinal cord cryosections for the NCC marker HNK1 [26] and the primary cilium marker Arl13B (Figure 1D-J) [27]. These multipotent stem cells bore a primary cilium during their early migration before arriving at the dorsal root level (white arrows, Figure 1E,F). Migrating NCCs reached the ventral roots at HH17 (Figure 1B,G) and the area lateral of the notochord at HH18 (Figure 1C,I). During migration and settlement, we found primary cilia located on the soma of NCCs (white arrows, Figure $1 \mathrm{H}, \mathrm{J}$ ). In fact, $88 \pm 5 \%$ of HH18 migrating NCCs bore a primary cilium, with an average primary cilium length of $2.1 \pm 0.5 \mu \mathrm{m}$ (mean \pm standard deviation, $\mathrm{N}($ embryos) $=3$; see also Figure 5 for a summary of the data on length and ciliation ratio).

Taken together, our data revealed that just after undergoing epithelial-to-mesenchymal transition and delamination, NCCs already bore a primary cilium and maintained it during their migration and early settlement. 


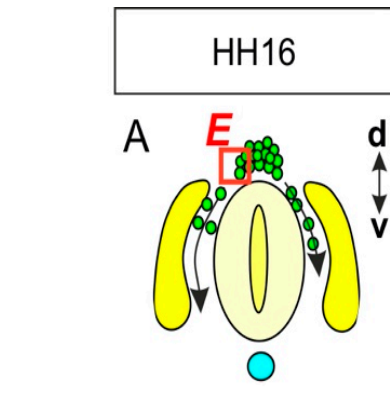

$\mathrm{HH} 17$

\begin{tabular}{|l|l|}
\hline HH18 & $\begin{array}{c}\text { HNK1 Arl13B } \\
\text { Hoechst }\end{array}$ \\
\hline
\end{tabular}
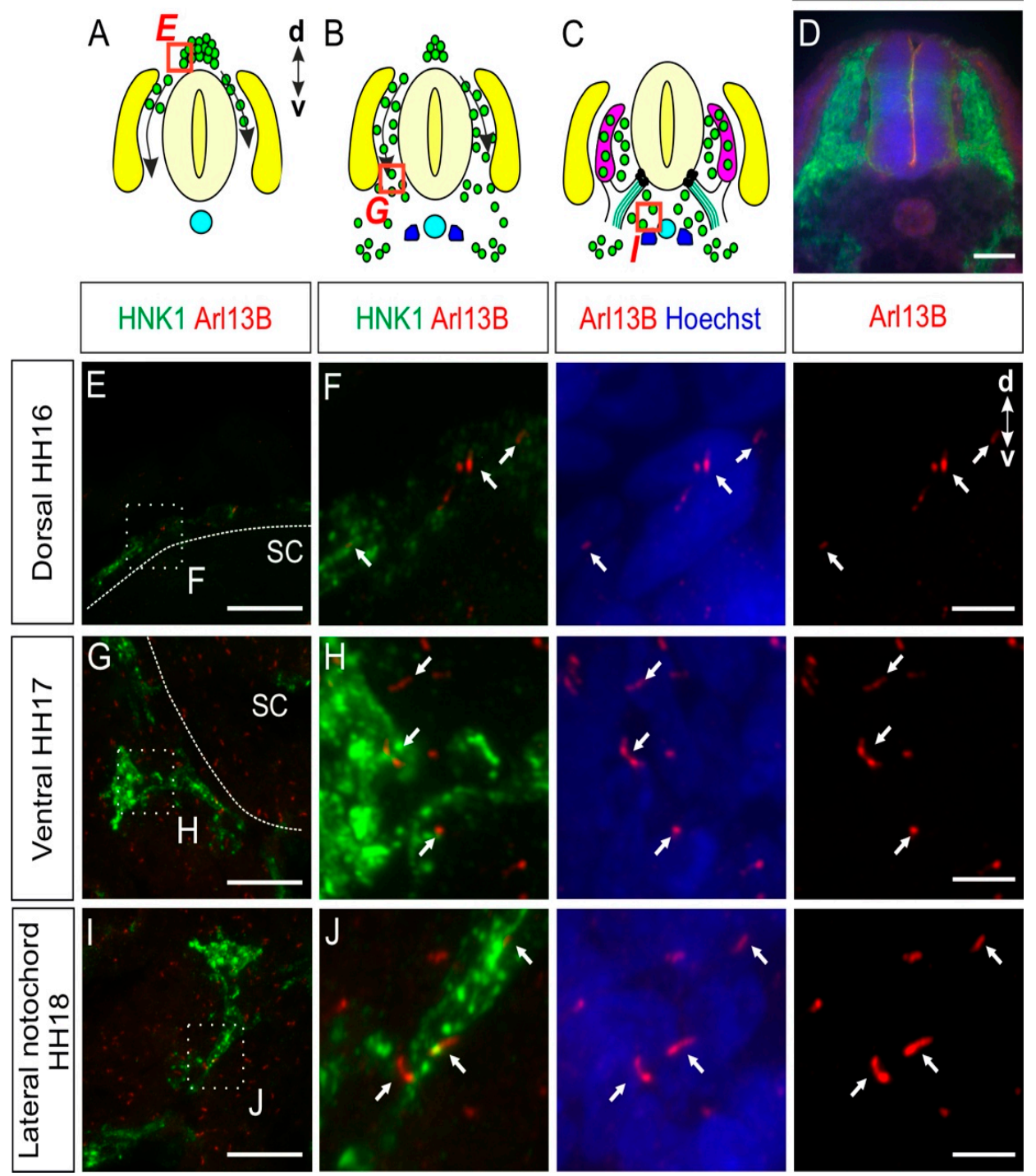

Figure 1. Trunk neural crest cells (NCCs) possess a primary cilium during early migration and settlement. (A-C) Trunk NCCs migrate ventrally between HH16 and HH18 on both sides of the neural tube. Green: NCCs, turquoise: notochord, purple: dorsal root ganglia (DRG), yellow: dermomyotome, blue: sympathetic ganglia chain, black dots: boundary cap cells (BCCs), green lines: ventral roots. d, dorsal; v, ventral. (D) A transverse section of the spinal cord of an HH18 embryo stained with HNK1 to stain NCCs (green) and with Arl13B antibodies to visualize primary cilia (red). Nuclei were counterstained with Hoechst (blue). (E,F) NCCs were visualized at HH16 before arriving at the dorsal root level. They were found to bear a primary cilium (white arrows). (G-J) NCCs located at the ventral root level (G) and the area lateral to the notochord (I) possessed a primary cilium (white arrows). Squares with dashed lines represent the region of interest shown in the right panels. Dashed lines represent the boundary of the spinal cord. d, dorsal; v, ventral; SC, spinal cord. Scale bars: 100 (D), $25(\mathbf{E}, \mathbf{G}, \mathbf{I})$, and $5 \mu \mathrm{m}(\mathbf{F}, \mathbf{H}, \mathbf{J})$.

\subsection{Dorsal Root Ganglia Neurons Carry a Primary Cilium during Development}

We then asked whether the primary cilium was maintained in NCC derivatives during development. We first focused on the sensory neurons located in the DRG. We found that the first Islet-1-positive, differentiated DRG neurons carried a primary cilium at HH18 (white arrows, Figure 2A). Interestingly, Islet-1-negative cells in the DRG also had a primary cilium, suggesting that either neuronal or Schwann cell precursors were ciliated (open arrow, Figure 2A). Certainly at HH26, 1E8-positive Schwann cell precursors located in DRG bore a primary cilium (arrows, Figure S1). At HH26 and HH30, cilia were evenly 
distributed throughout the DRG (white arrows, Figure 2B,C). We found that $86 \pm 5 \%$ of Hoechst-positive cells carried a primary cilium in HH26 DRG. Given the fact that $75 \pm 3 \%$ of these cells were Islet-1-positive (mean \pm standard deviation, $\mathrm{N}$ (embryos) $=3$, $n(D R G)=12)$, this suggested that the large majority of DRG neurons were ciliated at this stage (see also Figure 5). The average length of primary cilia in DRG was of $2.2 \pm 0.5 \mu \mathrm{m}$ (mean \pm standard deviation, $\mathrm{N}($ embryos $)=3, \mathrm{n}(\mathrm{DRG})=12$ ). In line with these results, we made similar observations in mice at embryonic day E11.5, at the time when DRG afferents enter the spinal cord (white arrows, Figure 2D) [28].

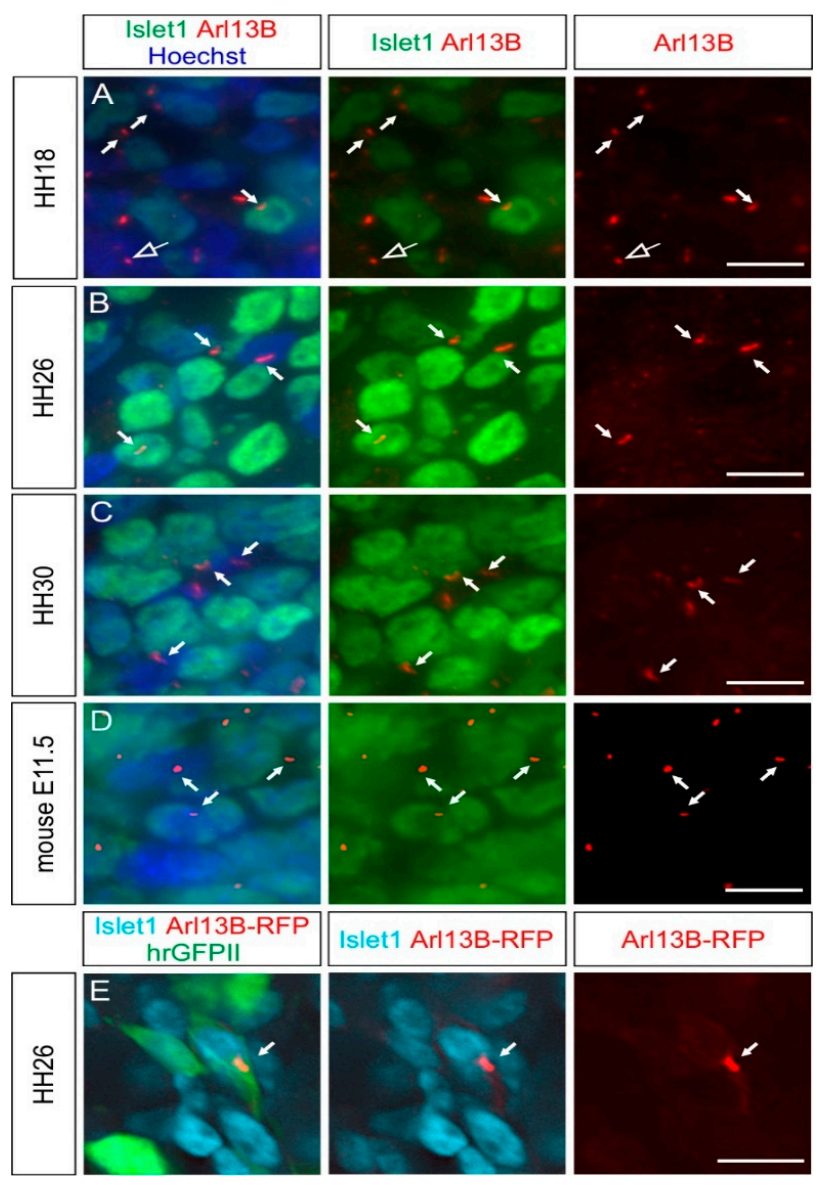

Figure 2. Embryonic DRG neurons possess a primary cilium in chicken and mouse embryos. (A-D) Micrographs of Islet1-positive DRG neurons (green) bearing an Arl13B-positive primary cilium (red, white arrows) at stage $\mathrm{HH} 18, \mathrm{HH} 26$, and HH30. The open arrow points to a primary cilium on an Islet-1-negative cell. (D) E11.5 mouse DRG neurons also possessed a primary cilium (white arrows). Nuclei were counterstained with Hoechst (blue). (E) Primary cilia were visible after RFP staining (red) of HH26 Islet-1-positive DRG neurons (cyan) after coelectroporation of Arl13B-RFP (white arrow) with hrGFPII (green). Dorsal is up. Scale bars: 10 (A-D) and $5 \mu \mathrm{m}$ (E).

We validated the staining of cilia obtained with antibodies against Arl13B with staining for the intraflagellar transport protein IFT88 (arrows, Figure S2A) [29]. Furthermore, we utilized in ovo electroporation to transfect Arl13B-RFP in NCCs and their derivatives and could reveal the presence of primary cilia in Islet-1-positive DRG neurons (white arrow, Figure 2E).

Altogether, these results show that DRG neurons maintain their primary cilium when they polarize, send their axons towards the periphery and the CNS, and connect to the deeper layers of the spinal cord [30]. 


\subsection{Boundary Cap Cells Bear a Primary Cilium at Both Ventral and Dorsal Roots}

During the assembly of chicken trunk PNS, a subtype of migrating NCCs, the boundary cap cells (BCCs), will first stop and cluster at the ventral roots exit points (also termed motor axon exit points) of the spinal cord around HH18, as revealed by $1 \mathrm{E} 8$ immunostaining, recognizing the $\mathrm{P} 0$ protein (white open arrowheads, Figure $3 \mathrm{~A}$ ). Later, BCCs will do the same at the dorsal root entry zone level (white arrowheads, Figure 3A). BCCs are located at the interface between the CNS and the PNS. They play a role as gatekeepers between the CNS and the PNS, and they represent stem cells that later contribute to subtypes of sensory neurons, glial cells, and pericytes [31,32]. Using coimmunostaining of the BCC marker $1 \mathrm{E} 8$ and the primary cilium marker Arl13B, we were able to see that ventral and dorsal BCCs bore a primary cilium at all stages investigated in vivo (HH18-HH30; white arrows, Figure 3B-E and Figure S3). We quantified that $87 \pm 5 \%$ of dorsal BCCs and $90 \pm 3 \%$ of ventral $\mathrm{BCC}$ s were ciliated at $\mathrm{HH} 26$, with an average length of primary cilia of $2.8 \pm 0.5 \mu \mathrm{m}$ (dorsal BCC) and $3 \pm 0.6 \mu \mathrm{m}$ (ventral BCC; mean \pm standard deviation, $\mathrm{N}(\mathrm{embryos})=3$; see also Figure 5). Moreover, we could confirm the ciliation of BCCs at HH26 with IFT88 staining (arrows, Figure S2C,D).

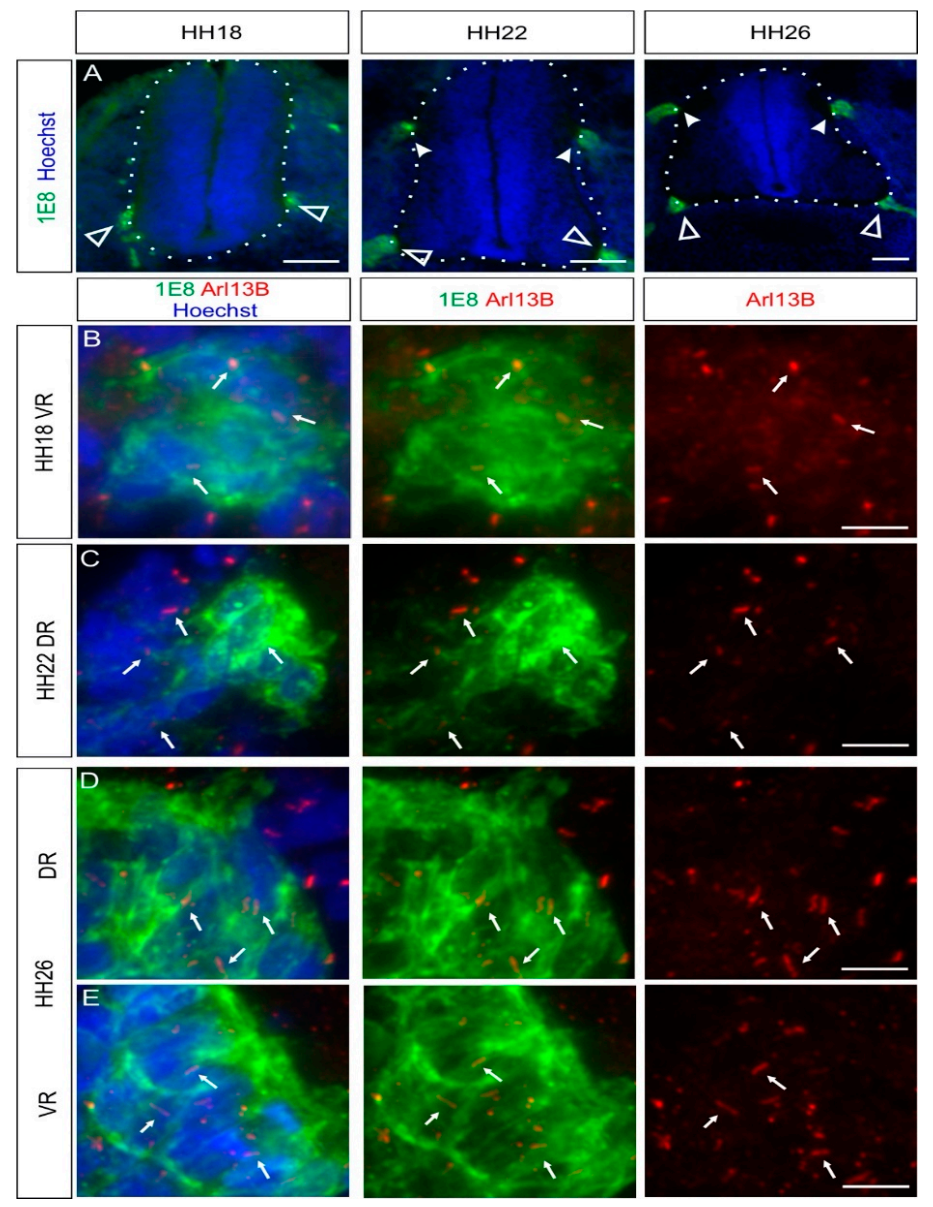

Figure 3. BCCs possess a primary cilium during the early development of the central nervous system (CNS)-peripheral nervous system (PNS) boundary. BCCs were stained with 1E8 antibodies (green) and primary cilia with Arl13B antibodies (red). (A) BCC clusters were initially detected at the ventral roots at HH18 (white open arrowheads). BCC clusters at the dorsal roots were observed at HH22 (white arrowheads). Nuclei were counterstained with Hoechst (blue). (B-E) BCCs were ciliated at both dorsal and ventral roots between $\mathrm{HH} 18$ and $\mathrm{HH} 26$ (white arrows). White dashed lines represent the boundary of the spinal cord (CNS). DR, dorsal roots; VR, ventral roots. Dorsal is up. Scale bars: 100 (A) and $10 \mu \mathrm{m}(\mathbf{B}-\mathbf{E})$. 
Overall, our results indicate that BCCs bear a primary cilium throughout the early stages of development when neural circuits in the PNS and the CNS are formed.

\subsection{Carrying a Primary Cilium Appears to Be a Common Feature on NCC Derivatives In Vivo}

To further complement our in vivo characterization of ciliation, we also assessed two other populations of NCC derivatives: the sympathetic ganglia (SG) neurons and the melanocytes.

SG neurons are located in the SG chains and are part of the autonomic nervous system [33]. Coimmunostaining of the SG neuron markers Islet-1 or Tyrosine hydroxylase $(\mathrm{TH})$, together with the primary cilia marker Arl13B, revealed that these neurons were ciliated at HH26 (white arrows, Figure 4A,B). We found that $96 \pm 2 \%$ of SG neurons carried a primary cilium, with an average length of $2.5 \pm 0.9 \mu \mathrm{m}$ (mean \pm standard deviation, $\mathrm{N}($ embryos) $=3$; Figure 5). The ciliation of these neurons was also confirmed by IFT88 staining of primary cilia (arrows, Figure S2B).

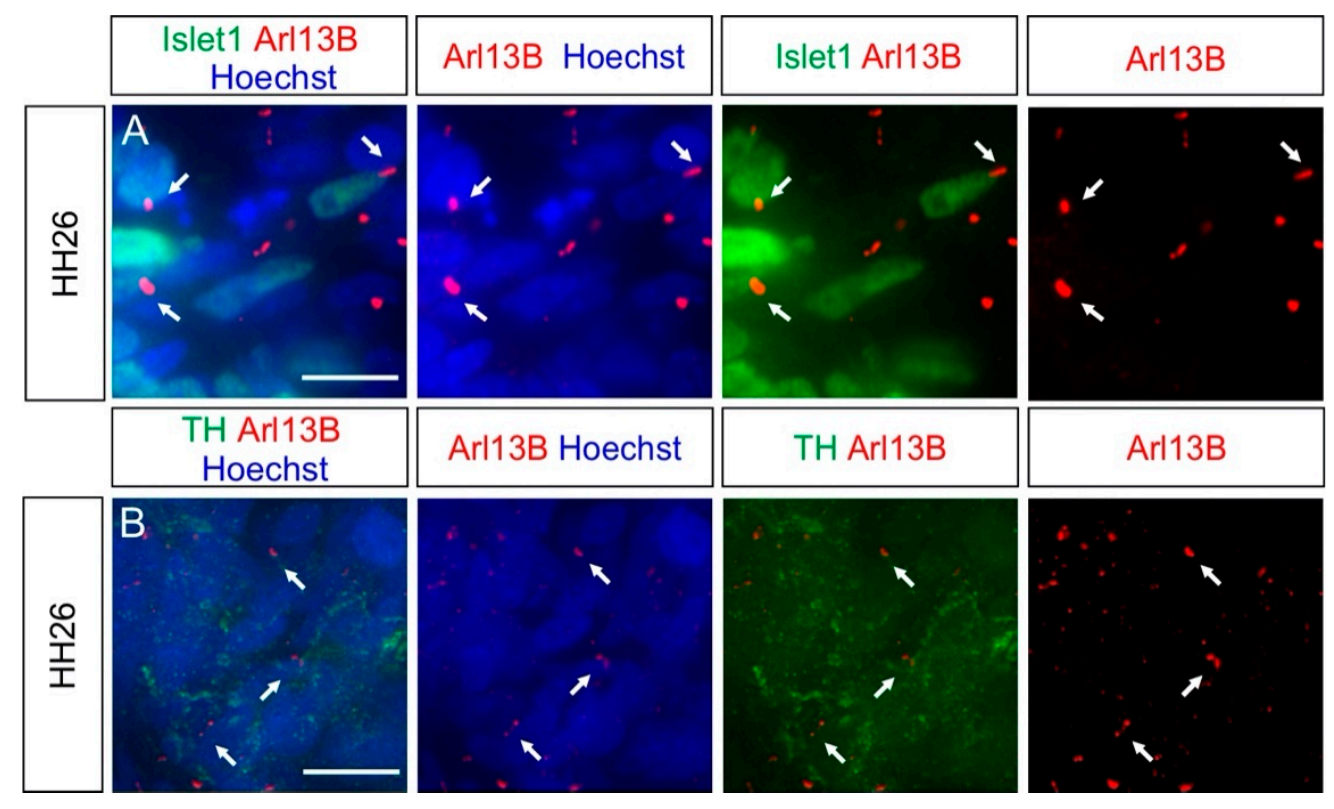

Figure 4. Other NCC derivatives, such as sympathetic ganglia (SG) neurons, possess a primary cilium. Islet-1 (A) and TH (B) antibodies were used to stain HH26 SG neurons (green). (A,B) Arl13B staining revealed that these neurons were ciliated (white arrows). Nuclei were counterstained with Hoechst (blue). Dorsal is up. TH, tyrosine hydroxylase. Scale bars: $10 \mu \mathrm{m}$.

A subset of trunk NCCs after delamination will migrate dorsolaterally and constitute the melanocyte lineage to ultimately form melanocytes in the skin [23,25]. We visualized melanocytes in the skin of the trunk at HH26 using the MelEM antibody and could see that these cells bore a primary cilium, with Arl13B costaining (white arrows, Figure S4). In fact, $93 \pm 4 \%$ of these cells bore a primary cilium, with an average length of $1.6 \pm 0.6 \mu \mathrm{m}$ (mean \pm standard deviation, N(embryos) $=3$; Figure 5).

Collectively, our results showed that both SG neurons during their early development and melanocytes located in the skin bore a primary cilium.

Taken together, our qualitative and quantitative assessments of ciliation of neural crest cells and their derivatives demonstrate that they all bear a primary cilium during development. Moreover, the percentage of ciliation is really high, with around $90 \%$ of cells in each population carrying a cilium. There is some variability in ciliary length within each cell population and also between cell types. However, it is not clear to what extent these differences reflect variability in length measurements due to ciliary orientation. 

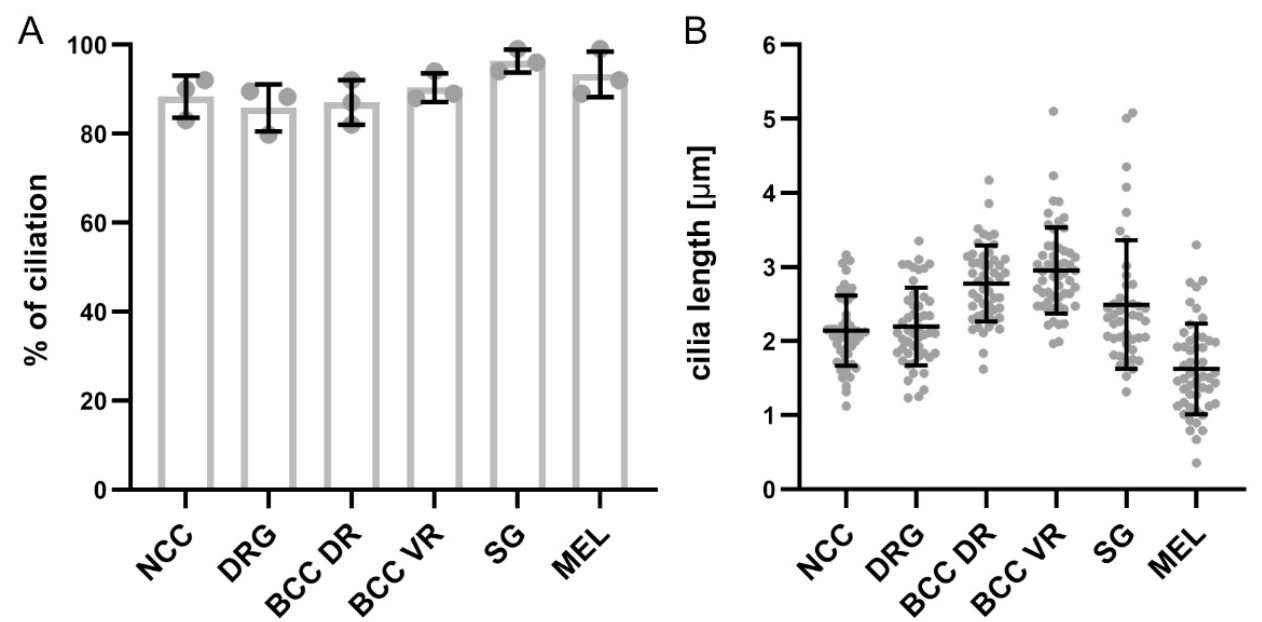

Figure 5. Quantification of the percentage of ciliated cells and ciliary length in NCCs and their derivatives. (A) Graph showing the average percentage of ciliation in migrating NCCs at HH18 and NCC derivatives at HH26. Note that for DRG, the average percentage of Hoechst-positive cells bearing a cilium is shown. (B) Graph showing the average cilia length in migrating NCCs at HH18 and NCC derivatives at HH26. Error bars represent standard deviation. Data points represent the average percentage for each embryo (A) and single data points of cilia length that were measured (B), respectively. DR, dorsal roots; VR, ventral roots, MEL, melanocytes.

\subsection{Cultured Neurons Reveal Heterogeneity in Their Ciliation}

Since in vitro studies using dissociated neurons and neural explants have been widely used to investigate molecular mechanisms during neurodevelopment [34], it is important to assess whether primary cilia persist in these cultures.

We first used HH30 DRG primary neurons and cultured them for 1, 2, 5, or 7 days in vitro (DIV). We stained them for the neuronal DRG markers Islet-1 and Arl13B to reveal primary cilia (Figure 6A-D). We rarely observed Arl13B-positive cilia in these cultures. In fact, quantifications indicated that the average ciliation rate of DRG neurons was invariably around $20 \%$ at all culture times (Figure $6 \mathrm{~F}$ and Table $1 ; p \geq 0.05$ ). Noteworthy, the large majority of Schwann cells located in DRG, which were cocultured with DRG neurons and costained with 1E8 antibodies, carried a primary cilium already after 1DIV (white arrowhead, Figure 6E). Quantifications showed that between $80 \%$ and $90 \%$ of them carried a primary cilium after 1,2,5, or 7 DIV without any significant difference between culture times (Figure $6 \mathrm{G}$ and Table $1 ; p \geq 0.05$ ). This suggested that the culture conditions were not incompatible with ciliogenesis or cilia maintenance. We then examined the ciliation of HH30 DRG neurons cultured as explants after 1 DIV. In contrast to the culture of dissociated cells, we found that the majority of DRG neurons bore a primary cilium (white arrows, Figure $6 \mathrm{H}$ ). On average, $83 \pm 2 \%$ of Hoechst-positive cells had a primary cilium. Of those cells, $93 \pm 1 \%$ were Islet-1-positive DRG neurons (mean \pm standard deviation, $n=12$ explants, $\mathrm{N}=3$ replicates).

Table 1. Percentage of ciliation of dissociated neurons. Detailed values for Figures 6 and 7.

\begin{tabular}{|c|c|c|c|c|c|c|c|c|}
\hline & \multicolumn{4}{|c|}{ DRG } & \multicolumn{4}{|c|}{ Schwann Cells } \\
\hline & $1 \mathrm{DIV}$ & $2 \mathrm{DIV}$ & $5 \mathrm{DIV}$ & $7 \mathrm{DIV}$ & $1 \mathrm{DIV}$ & $2 \mathrm{DIV}$ & $5 \mathrm{DIV}$ & $7 \mathrm{DIV}$ \\
\hline average: & $19 \%$ & $20 \%$ & $25 \%$ & $24 \%$ & $89 \%$ & $90 \%$ & $81 \%$ & $92 \%$ \\
\hline standard deviation: & $6 \%$ & $6 \%$ & $6 \%$ & $7 \%$ & $5 \%$ & $5 \%$ & $3 \%$ & $3 \%$ \\
\hline \multirow[t]{3}{*}{ N(replicates): } & 5 & 5 & 5 & 5 & 3 & 3 & 3 & 3 \\
\hline & \multicolumn{4}{|c|}{ Commissural Neurons } & \multicolumn{4}{|c|}{ Motor Neurons } \\
\hline & $1 \mathrm{DIV}$ & 2 DIV & $5 \mathrm{DIV}$ & $7 \mathrm{DIV}$ & $1 \mathrm{DIV}$ & $2 \mathrm{DIV}$ & $5 \mathrm{DIV}$ & $7 \mathrm{DIV}$ \\
\hline average: & $66 \%$ & $68 \%$ & $66 \%$ & $76 \%$ & $48 \%$ & $47 \%$ & $80 \%$ & $85 \%$ \\
\hline standard deviation: & $4 \%$ & $6 \%$ & $7 \%$ & $5 \%$ & $8 \%$ & $4 \%$ & $9 \%$ & $7 \%$ \\
\hline N(replicates): & 4 & 4 & 4 & 4 & 6 & 6 & 4 & 4 \\
\hline
\end{tabular}




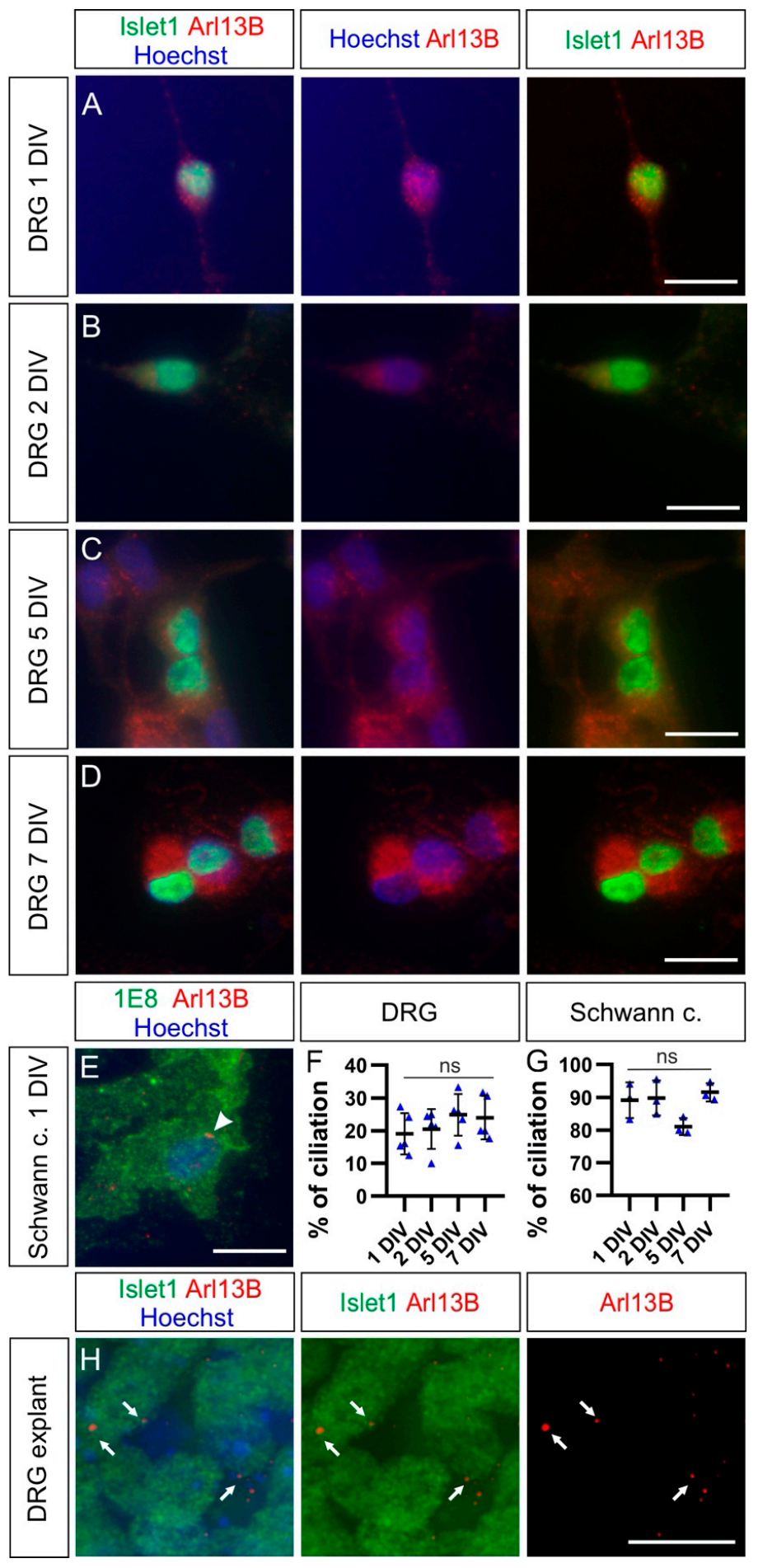

Figure 6. DRG neurons bear a primary cilium in explants but not in dissociated cultures. (A-D) Dissociated DRG neurons cultured for 1, 2, 5, or 7 days in vitro (DIV) were stained for Islet1 (green) together with Arl13B (red), revealing primary cilia, and counterstained with Hoechst (blue) to visualization nuclei. No clear Arl13B-positive ciliary structures could be seen on these cells. (E) Most Schwann cells possessed a primary cilium in dissociated cell culture (white arrowhead). (F,G) Quantification of the average percentage of ciliation in dissociated cultures of DRG neurons and Schwann cells up to one week of culture. Error bars represent standard deviations. Kruskal-Wallis test with Dunn's multiple-comparisons test (F) and one-way ANOVA with Dunn's multiple-comparisons test (G). $p \geq 0.05$, ns. (H) Islet1-positive DRG neurons in DRG explants possessed a primary cilium (red) after 1 DIV (white arrows). Schwann c., Schwann cells. Scale bars: $15 \mu \mathrm{m}$. 


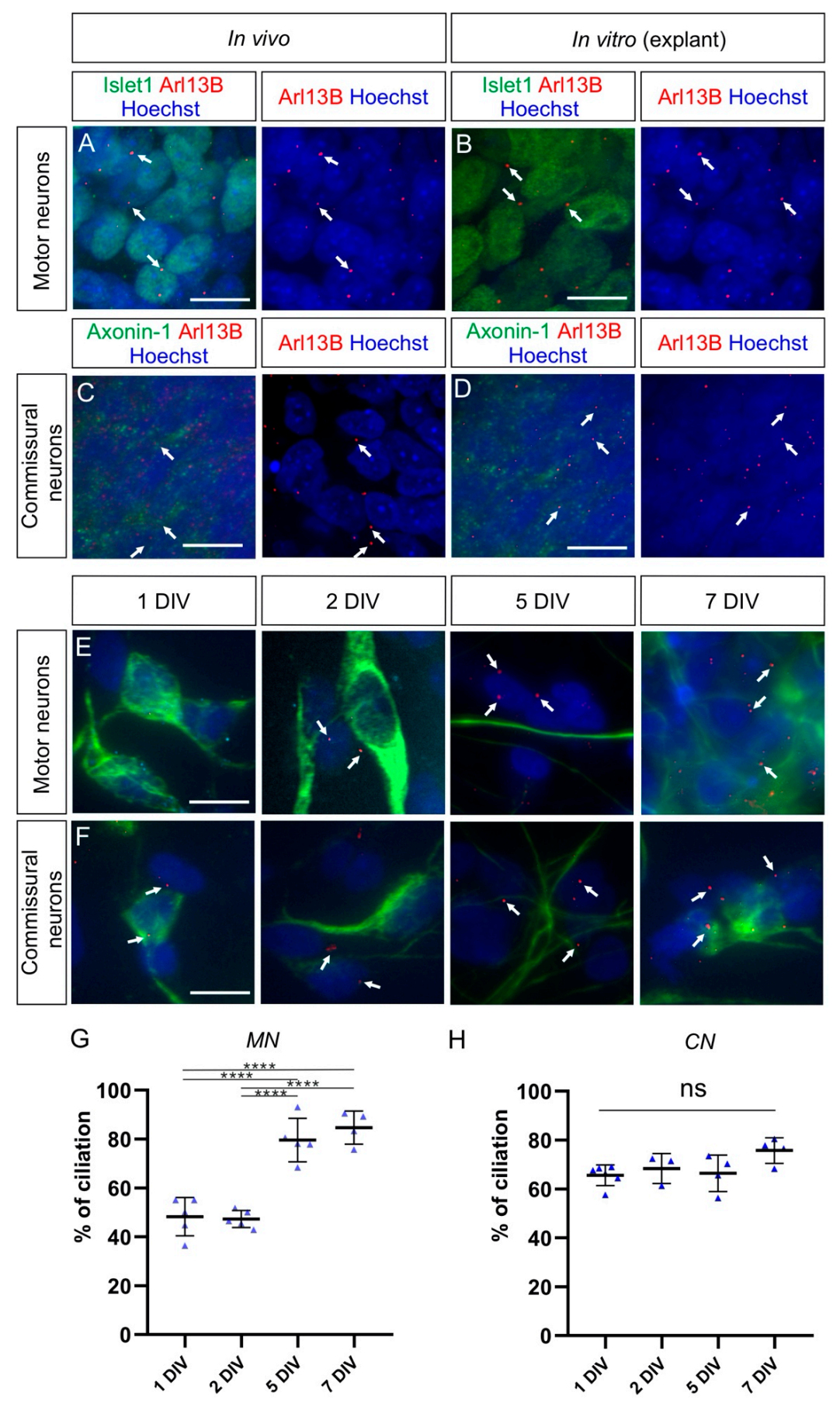

Figure 7. Commissural neurons and motor neurons possess a primary cilium in vivo and in explants cultures, but the ciliation rate is distinct for each population in dissociated cell cultures. (A) Islet-1-positive motoneurons located in the ventral horn of the spinal cord bore a primary cilium at HH26 in vivo (white arrows). (B) Motoneurons also possessed a primary cilium in explants cultured for 1 DIV (white arrows). (C) Axonin-1-positive commissural neurons, located in the dorsal horn of the spinal cord, carried a primary cilium at HH26 in vivo (white arrows). (D) Commissural neurons also possessed a primary cilium in explants cultured for 1 DIV (white arrows). (E,F) Cultured dissociated motoneurons (E) and commissural neurons (F), stained for neurofilament (NF-M), carried a primary cilium stained with Arl13B at different levels after 1, 2, 5, and 7 DIV (white arrows). (G) About half of the dissociated motoneurons carried a primary cilium after 1 and 2 DIV, and the ciliation rate significantly increased up to around 80\% after 5 and 7 DIV. One-way ANOVA with Dunn's multiple-comparisons test. (H) More than $65 \%$ of cultured dissociated commissural neurons carried a primary cilium after 1 DIV and kept it to a similar level up to 7 DIV. Kruskal-Wallis test with Dunn's multiple-comparisons test. Error bars represent standard deviations. $p \geq 0.05$, ns; $p<0.0001{ }^{* * * *}$. MN, motoneurons; $\mathrm{CN}$, commissural neurons. Scale bars: $10 \mu \mathrm{m}$. 
As DRG neurons belong to the PNS and cannot consistently regain a primary cilium when cultured as dissociated neurons, we assessed and compared the ciliation rate of CNS neurons in culture. As seen for DRG neurons in vivo, spinal cord neurons carried a cilium in vivo at $\mathrm{HH} 26$. We found a primary cilium on most of the dorsally-located contactin2/axonin-1-positive commissural neurons and the ventrally-located Islet-1-positive motoneurons (white arrows, Figure 7A,C). Robust ciliation was still observed in both motoneurons and commissural neurons cultured as explants (white arrows, Figure 7B,D). Interestingly, the ciliation of dissociated motoneurons was around 50\% after 1 and 2 DIV, then it significantly increased up to around $80 \%$ after 5 DIV and stayed at a similar level after 7 DIV (Figure $7 \mathrm{G}$ and Table $1 ; p<0.0001)$. In contrast, the majority $(\sim 66 \%)$ of dissociated commissural neurons carried a primary cilium already after 1 DIV and maintained it at a similar level up to 7 DIV (Figure $7 \mathrm{H}$ and Table $1 ; p \geq 0.05$ ).

Taken together, our culture experiments showed that DRG neurons are only robustly ciliated when cultured as explants. When cultured as dissociated cells, they lost the primary cilium and were unable to regain it. This is in contrast to neuronal populations from the CNS, such as motoneurons and commissural neurons of the spinal cord, where cilia were maintained or regained after some days in dissociated cultures.

\section{Discussion}

In this study, we analyzed the presence of primary cilia in different cell populations of developing chicken PNS, between HH16 and HH30 in vivo. Our data showed that NCCs and their derivatives carried a primary cilium during the early and later stages of PNS formation (Figures 1-5, Figures S1 and S2).

We could see that migrating NCCs carried a primary cilium while migrating to their final locations, where they settle and differentiate (Figure 1). This observation suggests that already at a very early stage of trunk PNS formation, the primary cilium might potentially play a role in the migration and correct settlement of the NCCs. Interestingly, in human ciliopathies, patients have very often an abnormal development of the craniofacial complex, which suggests aberrant cranial NCC migration [35]. In line with this, studies using animal models of ciliopathies suggest that cranial NCC migration and development are impaired in a cell-autonomous manner when primary cilia are compromised. A lack of a functional primary cilium led to defects in the development of several organs, such as the heart, cranial structures, the tongue, and the submandibular gland [36-42]. Interestingly, NCC development at the trunk level involves signaling pathways, such as Wnt, Sonic Hedgehog, TGF $\beta$, or chemokine signaling, which are linked to the primary cilium or have components that have been shown to localize in it in other cell types [43-47]. Thus, a cell-autonomous role for primary cilia in early NCC development in the trunk is very likely. In line with this hypothesis, previous results have suggested a role for the primary cilium in trunk NCC differentiation in mice.

Secondly, we described the ciliation of differentiated sensory neurons within the DRG (Figure 2); DRG neurons connect the periphery to the CNS. According to our findings, they were ciliated at all the key stages: when they polarize (HH18), sending central afferents into the CNS and peripheral axons toward the periphery $(\mathrm{HH} 26)$, and when they produce collaterals growing within the deeper layers of the spinal cord (HH30, Figure 2A-C, respectively) [48,49]. In adult mice, DRG neurons were shown to bear a primary cilium, suggesting that they might maintain it after the PNS is formed [22]. Interestingly, silencing of the Joubert syndrome protein C5orf42 (also termed CPLANE1 or Jbts17) —a protein required for ciliogenesis-in chicken NCCs and neural tube led to obvious defects in the development of DRG central afferents and the sciatic nerve, suggesting that a functional primary cilium might play a role in the development of DRG axons at both the periphery and central afferent levels [21]. Furthermore, the loss of Bardet-Biedl syndrome proteins in mice was shown to lead to an alteration in sensory innervation in the skin, suggesting an abnormal development of peripheral sensory axons in ciliopathies [22]. Therefore, our results will be useful for further investigating the possible roles of a functional primary 
cilium in sensory neuron axonogenesis, axon guidance, and axon branching in vivo, given the fact that the DRG system is a very accessible system to study each one of these steps.

Another important population of NCC derivatives that we analyzed was the BCCs. BCCs bore a primary cilium at both the ventral and dorsal roots as soon as they clustered and maintained their cilium, at least until HH30 (Figure 3 and Figure S3). Several studies have demonstrated a role for these cells as a "gatekeeper" at the CNS-PNS boundary at the ventral root level by maintaining the soma of motoneurons in the ventral spinal cord by Semaphorin 6A-mediated repulsive signals $[31,50,51]$. In the dorsal roots, they might play a role in orchestrating the correct guidance of DRG central afferents into the spinal cord in higher vertebrates [52]. Interestingly, after C5orf42 knockdown in neural crest cells and neural tube, dorsal root formation and DRG patterning were aberrant [21]. It is possible that such phenotypes result from defects in the clustering of these cells at the dorsal root entry zone. Further experiments will be needed to verify this possibility. BCCs also serve as stem cell niches, and some of them keep proliferating after clustering [52]. In fact, BCCs contribute to subtypes of sensory neurons, Schwann cell precursors, and pericytes [32]. Therefore, it will be interesting to study in detail whether proliferating BCCs bear a primary cilium and whether a functional primary cilium would be required for their proliferation, as was shown for granule neuron progenitors of the developing cerebellum [53].

Additionally, to complement these results, we could also detect primary cilia on SG neurons and melanocytes at early stages (Figure 4 and Figure S4). As for DRG neurons, the presence of the primary cilium during the development of SG neurons might be of interest, although no hints at a possible role during their development have been reported yet. The presence of primary cilia in melanocytes is in line with observations made in the zebrafish [54].

Finally, we assessed the ciliation of different populations of neurons in vitro. We found that the widely used dissociated embryonic DRG neurons did not consistently recover their primary cilium in culture even after 7 DIV (Figure $6 \mathrm{E}-\mathrm{G}$ ). Only around $20 \%$ of DRG neurons carried an Arl13B-positive cilium. This was in contrast with previous data showing ciliation of P0 mouse hippocampal neurons after 7 DIV (Figure 6E-G) [55]. However, the majority of DRG neurons cultured as explants for 1 DIV was ciliated (Figure 6H). DRG neurons have been widely used to decipher molecular mechanisms of axonal outgrowth, axon guidance, and branching in vitro [56-58]. Interestingly, some of the major guidance receptors, such as Robo1 and Neuropilin-1, have recently been localized to the primary cilium of neurons in the CNS and mouse fibroblasts, respectively [43,59]. Hence, it is possible that some of the signaling pathways involved in axonal development might be transduced at the primary cilium level. Our results stress the fact that for in vitro studies investigating signaling pathways that might involve the primary cilium, a proper culture system should be carefully chosen. In the case of embryonic DRG neurons, DRG explants rather than dissociated cultures should be preferentially used.

Furthermore, we could also detect heterogeneity in the ciliation of CNS neurons compared to DRG neurons. The majority of commissural neurons and motoneurons carried a primary cilium when cultured as explants, as was the case for DRG neurons (Figure 7A-D). Dissociated commissural neurons were robustly ciliated already after 1 DIV, but for motoneurons, only after 5 DIV (Figure 7E-H). This suggests differences in the capacity for ciliogenesis in vitro among these neuronal cell types once they are dissociated: from being fast (commissural neurons) to slow (motoneurons) to inefficient (DRG neurons) in rebuilding a primary cilium. These differences might be due to changes in the expression of genes involved in ciliogenesis in a specific population of neurons compared to others $[60,61]$. The fact that only $50 \%$ of motoneurons can recover a primary cilium after 2 DIV might reflect a subpopulation-dependent difference. Further experiments using specific markers for specific subpopulations of motoneurons will be required to investigate this possibility. Moreover, there might be a general difference in the capacity of reciliation between CNS neurons and PNS neurons. Noteworthy, DRG neurons, under certain conditions, are able the regenerate their peripheral and central axons in vivo, 
whereas CNS neurons are not [62]. Therefore, it would be interesting to investigate the ciliation in DRG during axon regeneration as there might be some links between signaling cascades involved in regenerative responses and the primary cilium, as recently reported in retinal ganglion neurons [63].

Overall, the presence of primary cilia in NCCs and all their derivatives studied above in chicken embryos in vivo prompts further research to explore the role that the primary cilium might play during PNS formation. In particular, in ovo RNAi-based knockdown or CRISPR/Cas9-based knockout of specific genes will help to address these questions in more detail in chickens [64-67]. Our results pave the way for further studies to utilize chicken embryos as a model for deciphering the potential role of the primary cilium in neural circuit formation in the PNS.

\section{Materials and Methods}

\subsection{Embryo Dissection and Fixation}

The developmental stages of the chicken embryos were determined according to Hamburger and Hamilton [68]. The bodies were pinned down with insect pins (stainless steel pins) in a silicon-layered dish filled with cold PBS. The internal organs were removed until the vertebrae and the ribs were visible. For fixation, the extremities of older embryos (HH30) were shortened. Embryos were transferred to a new dish and fixed in $4 \%$ paraformaldehyde in PBS at room temperature for $1 \mathrm{~h}(\mathrm{HH} 18-\mathrm{HH} 26)$ or $2 \mathrm{~h}(\mathrm{HH} 30)$. Then, they were washed 3 times for 10 min with PBS at RT. For cryoprotection of the tissue, embryos were transferred to $25 \%$ sucrose in PBS and incubated for at least $24 \mathrm{~h}$ at $4{ }^{\circ} \mathrm{C}$. For cryosectioning, the tissue was embedded in OCT compound (Tissue-Tek, Sakura Finetek, Alphen aan den Rijn, Netherlands), frozen, and cut with a thickness of $25 \mu \mathrm{m}$ with a cryostat (Leica CM1850, Muttenz, Switzerland).

\subsection{In Ovo Electroporation}

In ovo electroporation was used to target neural crest cells in HH12-14 embryos, as described previously $[69,70]$. A DNA mix containing $25 \mathrm{ng} / \mu \mathrm{L} \beta$-actin::hrGFPII and $25 \mathrm{ng} / \mu \mathrm{L} \beta$-actin::Arl13B-RFP plasmids [71], diluted in PBS and 0.1\% Fast Green, was injected into the central canal of the neural tube and unilaterally electroporated using a BTX ECM830 square-wave electroporator (five pulses at $18 \mathrm{~V}$, with $50 \mathrm{~ms}$ duration each and a 1-s interpulse interval; BTX, Holliston, MA, USA), as previously described [70]. Eggs were then incubated for 3 more days at $39^{\circ} \mathrm{C}$ until embryos reached stage $\mathrm{HH} 26$.

\subsection{Immunohistochemistry}

To prevent unspecific antibody binding, transverse spinal cord sections were incubated in blocking buffer ( $5 \%$ FCS in PBS) containing $0.25 \%$ Triton X-100 for one hour in a humid chamber. They were then washed $3 \times$ for 10 min each with PBS containing $0.25 \%$ Triton X100 at room temperature. Primary antibody mixtures were prepared in blocking buffer and added to the slides (Table 2). Slides were incubated overnight at $4{ }^{\circ} \mathrm{C}$ in a humid chamber.

The next day, the spinal cord sections were washed $3 \times$ for $10 \mathrm{~min}$ each at room temperature with PBS/0.25\% Triton X-100. Afterward, secondary antibodies diluted in blocking buffer were added to each slide (Table 3). The slides were then incubated for $2 \mathrm{~h}$ in a humid chamber at room temperature, protected from light. Before mounting, the sections were counterstained with Hoechst (Invitrogen (Thermo Fisher Scientific, Waltham, MA, USA) catalog number H3570, $2.5 \mu \mathrm{g} / \mathrm{mL}$ in PBS) for $10 \mathrm{~min}$ at room temperature, followed by $3 \times 10$ min each washing with PBS/0.25\% Triton X-100 and $2 \times$ for 5 min each with PBS at room temperature. Afterward, the slides were either mounted with Mowiol/DABCO or further stained for primary cilia with the protocol outlined below. 
Table 2. List of primary antibodies used for immunohistochemistry and immunocytochemistry.

\begin{tabular}{|c|c|c|c|c|}
\hline Antigen & Species & Source & Cat\# & Dilution \\
\hline Arl13B & Rabbit (polyclonal) & $\begin{array}{l}\text { Proteintech Group } \\
\text { (Manchester, UK) }\end{array}$ & $\begin{array}{c}\text { 13967-1-AP, } \\
\text { RRID:AB_2121979 }\end{array}$ & 1:1000 \\
\hline Ift 88 & Rabbit (polyclonal) & Proteintech Group & $\begin{array}{c}\text { 17711-1-AP, } \\
\text { RRID:AB 2060867 }\end{array}$ & 1:1000 \\
\hline Islet1 (clone 40.2D6) & Mouse (monoclonal) & $\begin{array}{l}\text { DSHB (Iowa City, IA, } \\
\text { USA) }\end{array}$ & $\begin{array}{c}\text { 40.2D6, } \\
\text { RRID:AB_528315 }\end{array}$ & $\begin{array}{c}1: 30 \\
\text { (supernatant) }\end{array}$ \\
\hline MelEM & Mouse (monoclonal) & DSHB & $\begin{array}{c}\text { MelEM, } \\
\text { RRID:AB_531849 }\end{array}$ & $\begin{array}{c}1: 2 \\
\text { (supernatant) }\end{array}$ \\
\hline P0 (clone 1E8) & Mouse (monoclonal) & DSHB & 1E8, RRID:AB_2078498 & $\begin{array}{c}1: 2 \\
\text { (supernatant) }\end{array}$ \\
\hline HNK1 (clone 1C10) & Mouse (monoclonal) & DSHB & $\begin{array}{c}\text { 1C10, } \\
\text { RRID:AB_10570406 }\end{array}$ & $\begin{array}{c}1: 2 \\
\text { (supernatant) }\end{array}$ \\
\hline Axonin-1/Contactin-2 & Goat (polyclonal) & Sonderegger Lab & NA & $1: 1000$ \\
\hline Tyrosine Hydroxylase & Mouse (monoclonal) & DSHB & aTH, RRID:AB_528490 & $\begin{array}{c}1: 5 \\
\text { (supernatant) }\end{array}$ \\
\hline $\begin{array}{l}\text { Neurofilament-M } \\
\text { (clone RMO270) }\end{array}$ & Mouse (monoclonal) & $\begin{array}{l}\text { Invitrogen (Thermo } \\
\text { Fisher Scientific, } \\
\text { Waltham, MA, USA) }\end{array}$ & $\begin{array}{c}\text { RMO270, } \\
\text { RRID:AB_2315286 }\end{array}$ & $1: 250$ \\
\hline
\end{tabular}

Table 3. List of secondary antibodies used for immunostaining.

\begin{tabular}{|c|c|c|c|}
\hline Secondary Antibodies & Source & Cat\# & Dilution \\
\hline $\begin{array}{l}\text { Donkey-anti-mouse } \\
\text { IgG-Alexa-488 }\end{array}$ & $\begin{array}{c}\text { Invitrogen } \\
\text { (Thermor Fisher Scientific, } \\
\text { Waltham, MA, USA) }\end{array}$ & $\begin{array}{c}\text { A21202 } \\
\text { RRID:AB_141607 }\end{array}$ & 1:1000 \\
\hline Donkey-anti-rabbit-Cy3 & $\begin{array}{l}\text { Jackson ImmunoResearch } \\
\text { (West Grove, PA, USA) }\end{array}$ & $\begin{array}{c}\text { 715-165-152 } \\
\text { RRID: AB_2307443 }\end{array}$ & 1:1000 \\
\hline Donkey-anti-goat-Cy5 & Jackson ImmunoResearch & $\begin{array}{c}\text { 705-175-147 } \\
\text { RRID: AB_2340415 }\end{array}$ & $1: 1000$ \\
\hline Donkey-anti-Goat IgG-Alexa-488 & Invitrogen & $\begin{array}{c}\text { A11055 } \\
\text { RRID:AB_2534102 }\end{array}$ & 1:1000 \\
\hline
\end{tabular}

\subsection{Immunohistochemistry for Primary Cilia}

To reduce the nonciliary staining of Arl13b or IFT88 antibodies and to get clear ciliary staining, we had to adapt and optimize standard protocols. Reducing the incubation time with the primary antibody greatly increased the ratio of the signal in the cilia versus the signal outside the cilia. Importantly, to stain primary cilia in both CNS and PNS, no (additional) detergent was used. Primary cilia were stained with rabbit anti-Arl13B antibody or rabbit anti-IFT88 diluted at 1:1000 in 5\% FCS in PBS for $2 \mathrm{~h}$ at room temperature (Table 2). Following this incubation, the slides were washed 3 times with PBS for $10 \mathrm{~min}$ each, and a secondary antibody (donkey-anti-rabbit-Cy3), diluted at 1:1000 in blocking buffer, was given to slides for $2 \mathrm{~h}$ at room temperature (Table 3). Finally, the sections were washed $3 \times 10 \mathrm{~min}$ each with PBS and mounted as described above. Note that the cilia staining protocol was always performed after immunostaining of the marker of interest (see Materials and Methods Section 4.3); thus, the tissue was already permeabilized with Triton-X-100 detergent.

\subsection{Cultures of Dissociated Neurons}

For accessing the DRG, HH30 embryos were pinned down, as described for immunohistochemistry, and the ventral vertebrae and the spinal cord were removed to access the DRG. For motoneurons and commissural neurons, open-book preparations of spinal cords dissected from $\mathrm{HH} 26$ embryos were used, and stripes of tissue were cut at the ventral region (motor column) or the most dorsal region (commissural neurons) of the spinal cord with small spring scissors [70]. Each population was dissociated by a 20-min incubation 
at $37{ }^{\circ} \mathrm{C}$ in $0.25 \%$ Trypsin in PBS (Invitrogen, cat\# 15090-046) containing DNase (Roche (Basel, Switzerland), cat\# 101041590 01; final concentration: 0.2\%), followed by pelleting by centrifugation ( $5 \mathrm{~min}, 1000 \mathrm{rpm}$, room temperature) and trituration with a fire-polished Pasteur pipette in culture media. Finally, cells were resuspended in the respective culture medium (Table 4). N3 supplement was added to a final concentration of $100 \mu \mathrm{g} / \mathrm{mL}$ transferrin, $10 \mu \mathrm{g} / \mathrm{mL}$ insulin, $20 \mathrm{ng} / \mathrm{mL}$ triiodothyronine, $40 \mathrm{nM}$ progesterone, $200 \mathrm{ng} / \mathrm{mL}$ corticosterone, $200 \mu \mathrm{M}$ putrescine, and $60 \mathrm{nM}$ sodium selenite (all from Sigma, Buchs, Swizerland). Penicillin and streptomycin (Invitrogen, cat\# 15140-122) were added to the media for a final concentration of 100 units $/ \mathrm{mL}$ and $100 \mu \mathrm{g} / \mathrm{mL}$, respectively. Cells were plated in 8-well Lab-Tek plates (20,000 cells per well; Nunc (Thermo Fisher Scientific, Waltham, MA, USA), cat\# 177445) and cultured for the desired time at $37{ }^{\circ} \mathrm{C}$ with $5 \% \mathrm{CO}_{2}$. Lab-Tek plates were precoated with poly-L-lysine $(20 \mu \mathrm{g} / \mathrm{mL}$, Sigma, cat\# P-12374) and coated with $10 \mu \mathrm{g} / \mathrm{mL}$ laminin (Invitrogen, cat\# 23017-015). When neurons were cultured for more than 2 days, fresh medium was added every two days (half the volume of the old medium in the well was exchanged with a fresh one).

Table 4. Media contents for different cell populations in dissociated cell cultures and explants.

\begin{tabular}{|c|c|c|c|c|}
\hline Cell Populations & & & & \\
\hline DRG & $\begin{array}{c}\text { MEM with Glutamax } \\
\text { (Invitrogen, cat\# } \\
41090-028)\end{array}$ & $\begin{array}{c}\text { Albumax }(4 \mathrm{mg} / \mathrm{mL}, \\
\text { Invitrogen, cat\# } \\
11020-021)\end{array}$ & N3 & $\begin{array}{l}\text { NGF }(20 \mathrm{ng} / \mathrm{mL} ; \\
\text { Invitrogen, cat\# } \\
13290-010)\end{array}$ \\
\hline $\begin{array}{c}\text { Commissural neurons/motor } \\
\text { neurons }\end{array}$ & $\begin{array}{c}\text { MEM with Glutamax } \\
\text { (Invitrogen, cat\# } \\
41090-028)\end{array}$ & $\begin{array}{c}\text { Albumax }(4 \mathrm{mg} / \mathrm{mL}, \\
\text { Invitrogen, cat\# } \\
11020-021)\end{array}$ & N3 & $\begin{array}{c}\text { Pyruvate (1 mM; Sigma, } \\
\text { cat\# P5280) }\end{array}$ \\
\hline
\end{tabular}

Cells were fixed after 1, 2, 5, or 7 DIV by adding one volume of prewarmed $4 \%$ PFA in PBS to each well and incubation for $5 \mathrm{~min}$ at $37^{\circ} \mathrm{C}$ with $5 \% \mathrm{CO}_{2}$. Then, the medium-PFA mix was exchanged for prewarmed $4 \%$ PFA in PBS, and cells were incubated for another 15 min with the same conditions before being washed with PBS at room temperature.

\subsection{Explants Cultures}

For explant cultures, LabTek wells were coated with poly-L-lysine and laminin as described above. Explants of DRG, motoneurons, or commissural neurons were transferred directly into LabTek wells containing a total of $400 \mu \mathrm{L}$ medium (Table 4). After 1 DIV, $400 \mu \mathrm{L}$ of prewarmed $2 \%$ PFA, with $15 \%$ sucrose in PBS (fixation buffer), was added to gently fix the explants, as described previously [72]. Following $40 \mathrm{~min}$ of incubation at room temperature, the upper phase of the solution $(400 \mu \mathrm{L})$ was discarded, and $400 \mu \mathrm{L}$ of fresh fixation buffer was given. After incubation for another hour, the explants were washed $3 \times 10$ min each with PBS at room temperature.

\subsection{Immunocytochemistry}

Cells were permeabilized with $0.1 \%$ Triton-X 100 in PBS (for dissociated neurons) or $0.25 \%$ Triton-X 100 in PBS (for explants) for $4 \mathrm{~min}$ at room temperature. They were rinsed $3 \times$ for 5 min each with PBS and blocked 15 min with 5\% FCS in PBS (blocking buffer) at room temperature. Primary antibodies were diluted in blocking buffer and added to the cells for $1 \mathrm{~h}$ at room temperature (Table 2). Cells were washed again with PBS and incubated in secondary antibodies diluted in blocking buffer for $1 \mathrm{~h}$ at room temperature (Table 3). Cells were counterstained with Hoechst (2.5 $\mu \mathrm{g} / \mathrm{mL}$ in PBS, cat\# H3570) for $4 \mathrm{~min}$ at RT and rinsed $3 \times 5$ min each with PBS before mounting, as described above.

\subsection{Microscopy}

Images were taken with an Olympus BX61 upright microscope equipped with a spinning disk unit (BX-DSU, Olympus, Tokyo, Japan) and a $10 \times$ air objective (UPLFL PH 10×/0.30, Olympus), a $40 \times$ water objective (UAPO W/340 40×/1.15, Olympus), or a 
$60 \times$ oil objective (PLAPON O $60 \times / 1.42$, Olympus) and an Orca- $R^{2}$ camera (Hamamatsu, Shizuoka, Japan) with Olympus CellSens Dimension 2.2 software. Cilia were visualized with $60 \times$ or $40 \times$ objectives and images were acquired with 20 planes for $40 \times$ images, with a $0.32-\mu \mathrm{m}$ distance between planes. For $10 \times$ and $60 \times$ images, 3.54 and $0.24 \mu \mathrm{m}$ distances were applied, respectively. The number of planes was variable. High magnification images were 2D deconvolved (nearest neighbor) using Olympus CellSens Dimension 2.2 software. Maximum intensity z-projection was created with the same software, and all images were analyzed and equally modified in Fiji/ImageJ [73].

\subsection{Quantification of Ciliation Rate and Cilia Length}

To quantify the number of primary cilia in HH26 DRG in vivo and HH30 explants in vitro, Fiji/ImageJ was used with images acquired with the $40 \times$ objective. First, a 2 channel picture with Islet-1 (green) and Arl13B (red) was split into separate channels (Figure 8A). On the picture displaying the primary cilia (Arl13B, red), the "triangle" threshold was applied (Figure 8B). The picture showing the Islet-1-positive DRG neurons was used to select the region of interest of the DRG with the freehand selection tool (Figure 8C). This selection was transferred to the thresholded primary cilia picture (Figure 8D). Finally, cilia were automatically counted within the region of interest using the "count particles" option (0-1 circularity, $0.2 \mu \mathrm{m}^{2}$ minimum size; Figure 8E). The number of Hoechst-positive and Islet-1-positive cells in the region of interest was counted manually to calculate the percentage of ciliation within each DRG. To quantify the percentage of ciliation in dissociated cultures, the numbers of total and ciliated neurons/cells per picture were manually counted by an experimenter, blind to the experimental conditions, using Fiji/ImageJ. The percentage of ciliation per replicate was calculated as the average from 4 adjacent pictures taken in the center of the well. For other populations, like migrating NCCs, BCCs, SG neurons, and melanocytes, it was easier to identify the ciliated cell with certainty, and, therefore, it was possible to calculate the ciliation rates directly. The ciliary length was manually measured in maximum projections of a Z-stack using the tracing tool in ImageJ in all populations mentioned in the text. It is, therefore, possible that the average cilia length might be underestimated as primary cilia oriented in the Z-axis of the stack would appear shorter than what they really are.
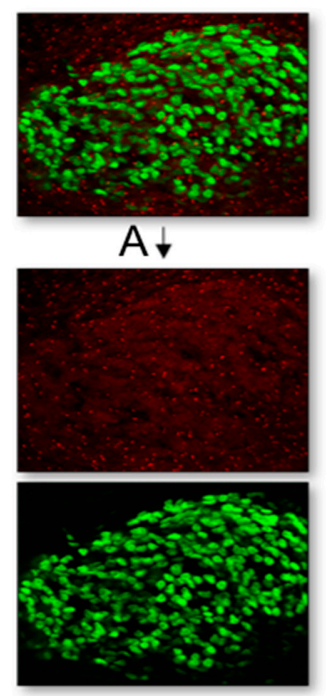
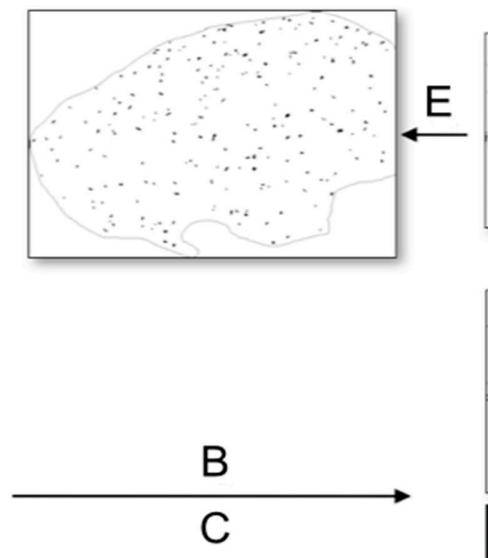

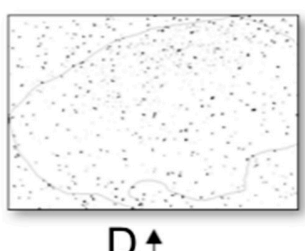

$\mathrm{D} \uparrow$

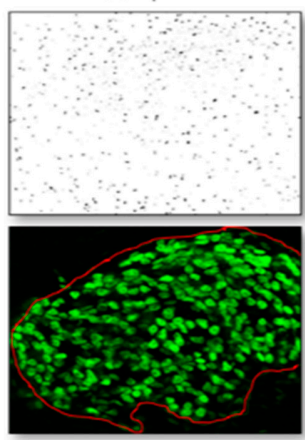

Figure 8. Workflow for quantification of primary cilia with the image analysis program Fiji. (A) First, a 2-channel picture with Islet-1 (green) and Arl13B (red) was split into separate channels. (B) On the picture displaying the primary cilia (Arl13B, red), the "triangle" threshold was applied. (C) The picture showing the Islet-1-positive DRG neurons was used to select the region of interest of the DRG with the freehand selection tool. (D) This selection was transferred to the thresholded primary cilia picture. (E) Finally, cilia were automatically counted within the region of interest using the "count particles" option. 


\subsection{Statistical Analysis}

Statistical analyses were carried out using GraphPad Prism 8 software. All data were assessed for normality (normal distribution) using the D'Agostino and Pearson omnibus K2 normality test and visual assessment of the normal quantile-quantile plot before choosing an appropriate (parametric or nonparametric) statistical test. All tests used in this study are mentioned either in the text or in the legend of figures.

Supplementary Materials: The following are available online at https: / /www.mdpi.com/1422-0 067/22/6/3176/s1, Figure S1: 1E8-positive Schwann cell precursors located in DRG are ciliated; Figure S2: Confirmation of the presence of a primary cilium on DRG neurons, SG neurons and BCC with IFT88 staining; Figure S3: Boundary Cap Cells (BCC) carried a primary cilium at HH30, both in dorsal and ventral roots; Figure S4: Melanocytes possessed a primary cilium in vivo.

Author Contributions: Conceptualization, A.D. and E.T.S.; methodology, E.Y. and A.D.; formal analysis, E.Y. and A.D.; investigation, E.Y. and A.D.; writing-original draft preparation, E.Y. and A.D.; writing-review and editing, E.Y., A.D., and E.T.S.; supervision, A.D. and E.T.S.; project administration, E.T.S.; funding acquisition, E.T.S. All authors have read and agreed to the published version of the manuscript.

Funding: This research was funded by the Swiss National Science Foundation.

Institutional Review Board Statement: Not applicable.

Informed Consent Statement: Not applicable.

Data Availability Statement: Not applicable.

Acknowledgments: We thank Raman Das (University of Manchester) for the Arl13B-RFP construct. We thank Alexander Hess for helping collect preliminary data in vivo.

Conflicts of Interest: The authors declare no conflict of interest. The funders had no role in the design of the study; in the collection, analyses, or interpretation of data; in the writing of the manuscript, or in the decision to publish the results.

$\begin{array}{ll}\text { Abbreviations } \\ \text { CNS } & \text { central nervous system } \\ \text { PNS } & \text { peripheral nervous system } \\ \text { DRG } & \text { dorsal root ganglia } \\ \text { BCC } & \text { boundary cap cells } \\ \text { NCC } & \text { neural crest cells } \\ \text { SG } & \text { sympathetic ganglia } \\ \text { HH } & \text { Hamburger and Hamilton stage } \\ \text { DIV } & \text { day in vitro }\end{array}$

\section{References}

1. Broekhuis, J.R.; Leong, W.Y.; Jansen, G. Regulation of Cilium Length and Intraflagellar Transport. In International Review of Cell and Molecular Biology; Elsevier: Amsterdam, The Netherlands, 2013; Volume 303, pp. 101-138. ISBN 978-0-12-407697-6.

2. Gerdes, J.M.; Davis, E.E.; Katsanis, N. The Vertebrate Primary Cilium in Development, Homeostasis, and Disease. Cell 2009, 137, 32-45. [CrossRef]

3. Oh, E.C.; Katsanis, N. Cilia in Vertebrate Development and Disease. Development 2012, 139, 443-448. [CrossRef]

4. Zimmermann, K.W. Beiträge zur Kenntniss einiger Drüsen und Epithelien: Hierzu Tafel XXVII, XXVIII u. XXIX. Arch. Mikrosk. Anat. 1898, 52, 552-706. [CrossRef]

5. Wong, S.Y.; Reiter, J.F. The Primary Cilium at the Crossroads of Mammalian Hedgehog Signaling. Curr. Top. Dev. Biol. 2008, 85, 225-260. [CrossRef] [PubMed]

6. Huangfu, D.; Anderson, K.V. Cilia and Hedgehog Responsiveness in the Mouse. Proc. Natl. Acad. Sci. USA 2005, 102, 11325-11330. [CrossRef]

7. Otto, E.A.; Schermer, B.; Obara, T.; O’Toole, J.F.; Hiller, K.S.; Mueller, A.M.; Ruf, R.G.; Hoefele, J.; Beekmann, F.; Landau, D.; et al. Mutations in INVS Encoding Inversin Cause Nephronophthisis Type 2, Linking Renal Cystic Disease to the Function of Primary Cilia and Left-Right Axis Determination. Nat. Genet. 2003, 34, 413-420. [CrossRef] [PubMed] 
8. Simons, M.; Gloy, J.; Ganner, A.; Bullerkotte, A.; Bashkurov, M.; Krönig, C.; Schermer, B.; Benzing, T.; Cabello, O.A.; Jenny, A.; et al. Inversin, the Gene Product Mutated in Nephronophthisis Type II, Functions as a Molecular Switch between Wnt Signaling Pathways. Nat. Genet. 2005, 37, 537-543. [CrossRef] [PubMed]

9. Schneider, L.; Clement, C.A.; Teilmann, S.C.; Pazour, G.J.; Hoffmann, E.K.; Satir, P.; Christensen, S.T. PDGFRalphaalpha Signaling Is Regulated through the Primary Cilium in Fibroblasts. Curr. Biol. 2005, 15, 1861-1866. [CrossRef] [PubMed]

10. Schmid, F.M.; Schou, K.B.; Vilhelm, M.J.; Holm, M.S.; Breslin, L.; Farinelli, P.; Larsen, L.A.; Andersen, J.S.; Pedersen, L.B.; Christensen, S.T. IFT20 Modulates Ciliary PDGFR $\alpha$ Signaling by Regulating the Stability of Cbl E3 Ubiquitin Ligases. J. Cell Biol. 2018, 217, 151-161. [CrossRef] [PubMed]

11. Boehlke, C.; Kotsis, F.; Patel, V.; Braeg, S.; Voelker, H.; Bredt, S.; Beyer, T.; Janusch, H.; Hamann, C.; Gödel, M.; et al. Primary Cilia Regulate MTORC1 Activity and Cell Size through Lkb1. Nat. Cell Biol. 2010, 12, 1115-1122. [CrossRef]

12. Satir, P.; Pedersen, L.B.; Christensen, S.T. The Primary Cilium at a Glance. J. Cell Sci. 2010, 123, 499-503. [CrossRef] [PubMed]

13. Mitchison, H.M.; Valente, E.M. Motile and Non-Motile Cilia in Human Pathology: From Function to Phenotypes: Motile and Non-Motile Ciliopathies. J. Pathol. 2017, 241, 294-309. [CrossRef] [PubMed]

14. Lee, J.E.; Gleeson, J.G. A Systems-Biology Approach to Understanding the Ciliopathy Disorders. Genome Med. $2011,3,59$. [CrossRef]

15. Ware, S.M.; Aygun, M.G.; Hildebrandt, F. Spectrum of Clinical Diseases Caused By Disorders of Primary Cilia. Proc. Am. Thorac. Soc. 2011, 8, 444-450. [CrossRef]

16. Hildebrandt, F.; Benzing, T.; Katsanis, N. Ciliopathies. N. Engl. J. Med. 2011, 364, 1533-1543. [CrossRef]

17. Grochowsky, A.; Gunay-Aygun, M. Clinical Characteristics of Individual Organ System Disease in Non-Motile Ciliopathies. Transl. Sci. Rare Dis. 2019, 4, 1-23. [CrossRef]

18. Guemez-Gamboa, A.; Coufal, N.G.; Gleeson, J.G. Primary Cilia in the Developing and Mature Brain. Neuron 2014, 82, 511-521. [CrossRef]

19. Suciu, S.K.; Caspary, T. Cilia, Neural Development and Disease. Semin. Cell Dev. Biol. 2020, S1084952119301727. [CrossRef]

20. Métin, C.; Pedraza, M. Cilia: Traffic Directors along the Road of Cortical Development. Neuroscientist 2014, 20, 468-482. [CrossRef] [PubMed]

21. Asadollahi, R.; Strauss, J.E.; Zenker, M.; Beuing, O.; Edvardson, S.; Elpeleg, O.; Strom, T.M.; Joset, P.; Niedrist, D.; Otte, C.; et al. Clinical and Experimental Evidence Suggest a Link between KIF7 and C5orf42-Related Ciliopathies through Sonic Hedgehog Signaling. Eur. J. Hum. Genet. 2018, 26, 197-209. [CrossRef]

22. Tan, P.L.; Barr, T.; Inglis, P.N.; Mitsuma, N.; Huang, S.M.; Garcia-Gonzalez, M.A.; Bradley, B.A.; Coforio, S.; Albrecht, P.J.; Watnick, T.; et al. Loss of Bardet Biedl Syndrome Proteins Causes Defects in Peripheral Sensory Innervation and Function. Proc. Natl. Acad. Sci. USA 2007, 104, 17524-17529. [CrossRef]

23. Etchevers, H.C.; Dupin, E.; Le Douarin, N.M. The Diverse Neural Crest: From Embryology to Human Pathology. Development 2019, 146, dev169821. [CrossRef]

24. Theveneau, E.; Mayor, R. Neural Crest Delamination and Migration: From Epithelium-to-Mesenchyme Transition to Collective Cell Migration. Dev. Biol. 2012, 366, 34-54. [CrossRef]

25. Marmigère, F.; Ernfors, P. Specification and Connectivity of Neuronal Subtypes in the Sensory Lineage. Nat. Rev. Neurosci. 2007, 8, 114-127. [CrossRef]

26. Giovannone, D.; Ortega, B.; Reyes, M.; El-Ghali, N.; Rabadi, M.; Sao, S.; De Bellard, M.E. Chicken Trunk Neural Crest Migration Visualized with HNK1. Acta Histochem. 2015, 117, 255-266. [CrossRef]

27. Caspary, T.; Larkins, C.E.; Anderson, K.V. The Graded Response to Sonic Hedgehog Depends on Cilia Architecture. Dev. Cell 2007, 12, 767-778. [CrossRef]

28. Dumoulin, A.; Schmidt, H.; Rathjen, F.G. Sensory Neurons: The Formation of T-Shaped Branches Is Dependent on a CGMPDependent Signaling Cascade. Neuroscientist 2021, 27, 47-57. [CrossRef]

29. Cole, D.G.; Diener, D.R.; Himelblau, A.L.; Beech, P.L.; Fuster, J.C.; Rosenbaum, J.L. Chlamydomonas Kinesin-II-Dependent Intraflagellar Transport (IFT): IFT Particles Contain Proteins Required for Ciliary Assembly in Caenorhabditis Elegans Sensory Neurons. J. Cell Biol. 1998, 141, 993-1008. [CrossRef]

30. Perrin, F.E.; Rathjen, F.G.; Stoeckli, E.T. Distinct Subpopulations of Sensory Afferents Require F11 or Axonin-1 for Growth to Their Target Layers within the Spinal Cord of the Chick. Neuron 2001, 30, 707-723. [CrossRef]

31. Fontenas, L.; Kucenas, S. Livin' On The Edge: Glia Shape Nervous System Transition Zones. Curr. Opin. Neurobiol. 2017, 47, 44-51. [CrossRef]

32. Radomska, K.J.; Topilko, P. Boundary Cap Cells in Development and Disease. Curr. Opin. Neurobiol. 2017, 47, 209-215. [CrossRef] [PubMed]

33. Ernsberger, U.; Rohrer, H. Sympathetic Tales: Subdivisons of the Autonomic Nervous System and the Impact of Developmental Studies. Neural Dev. 2018, 13, 20. [CrossRef] [PubMed]

34. Tojima, T.; Hines, J.H.; Henley, J.R.; Kamiguchi, H. Second Messengers and Membrane Trafficking Direct and Organize Growth Cone Steering. Nat. Rev. Neurosci. 2011, 12, 191-203. [CrossRef] [PubMed]

35. Schock, E.N.; Brugmann, S.A. Discovery, Diagnosis, and Etiology of Craniofacial Ciliopathies. Cold Spring Harb. Perspect. Biol. 2017, 9, a028258. [CrossRef] 
36. Elliott, K.H.; Millington, G.; Brugmann, S.A. A Novel Role for Cilia-Dependent Sonic Hedgehog Signaling during Submandibular Gland Development: Novel Role for Cilia-Dependent Shh Signaling During SMG Development. Dev. Dyn. 2018, $247,818-831$. [CrossRef]

37. Schock, E.N.; Struve, J.N.; Chang, C.-F.; Williams, T.J.; Snedeker, J.; Attia, A.C.; Stottmann, R.W.; Brugmann, S.A. A Tissue-Specific Role for Intraflagellar Transport Genes during Craniofacial Development. PLoS ONE 2017, 12, e0174206. [CrossRef] [PubMed]

38. Tian, H.; Feng, J.; Li, J.; Ho, T.-V.; Yuan, Y.; Liu, Y.; Brindopke, F.; Figueiredo, J.C.; Magee, W.; Sanchez-Lara, P.A.; et al. Intraflagellar Transport 88 (IFT88) Is Crucial for Craniofacial Development in Mice and Is a Candidate Gene for Human Cleft Lip and Palate. Hum. Mol. Genet. 2017, ddx002. [CrossRef]

39. Millington, G.; Elliott, K.H.; Chang, Y.-T.; Chang, C.-F.; Dlugosz, A.; Brugmann, S.A. Cilia-Dependent GLI Processing in Neural Crest Cells Is Required for Tongue Development. Dev. Biol. 2017, 424, 124-137. [CrossRef] [PubMed]

40. Portal, C.; Rompolas, P.; Lwigale, P.; Iomini, C. Primary Cilia Deficiency in Neural Crest Cells Models Anterior Segment Dysgenesis in Mouse. eLife 2019, 8, e52423. [CrossRef] [PubMed]

41. Tobin, J.L.; Di Franco, M.; Eichers, E.; May-Simera, H.; Garcia, M.; Yan, J.; Quinlan, R.; Justice, M.J.; Hennekam, R.C.; Briscoe, J.; et al. Inhibition of Neural Crest Migration Underlies Craniofacial Dysmorphology and Hirschsprung's Disease in Bardet-Biedl Syndrome. Proc. Natl. Acad. Sci. USA 2008, 105, 6714-6719. [CrossRef]

42. Willaredt, M.A.; Gorgas, K.; Gardner, H.A.R.; Tucker, K.L. Multiple Essential Roles for Primary Cilia in Heart Development. Cilia 2012, 1, 23. [CrossRef] [PubMed]

43. Higginbotham, H.; Eom, T.-Y.; Mariani, L.E.; Bachleda, A.; Hirt, J.; Gukassyan, V.; Cusack, C.L.; Lai, C.; Caspary, T.; Anton, E.S Arl13b in Primary Cilia Regulates the Migration and Placement of Interneurons in the Developing Cerebral Cortex. Dev. Cell 2012, 23, 925-938. [CrossRef] [PubMed]

44. Monaco, S.; Baur, K.; Hellwig, A.; Hölzl-Wenig, G.; Mandl, C.; Ciccolini, F. A Flow Cytometry-Based Approach for the Isolation and Characterization of Neural Stem Cell Primary Cilia. Front. Cell. Neurosci. 2019, 12, 519. [CrossRef]

45. Maj, E.; Künneke, L.; Loresch, E.; Grund, A.; Melchert, J.; Pieler, T.; Aspelmeier, T.; Borchers, A. Controlled Levels of Canonical Wnt Signaling Are Required for Neural Crest Migration. Dev. Biol. 2016, 417, 77-90. [CrossRef] [PubMed]

46. Bhatt, S.; Diaz, R.; Trainor, P.A. Signals and Switches in Mammalian Neural Crest Cell Differentiation. Cold Spring Harb. Perspect. Biol. 2013, 5. [CrossRef]

47. Clement, C.A.; Ajbro, K.D.; Koefoed, K.; Vestergaard, M.L.; Veland, I.R.; Henriques de Jesus, M.P.R.; Pedersen, L.B.; Benmerah, A.; Andersen, C.Y.; Larsen, L.A.; et al. TGF- $\beta$ Signaling Is Associated with Endocytosis at the Pocket Region of the Primary Cilium. Cell Rep. 2013, 3, 1806-1814. [CrossRef]

48. Dumoulin, A.; Ter-Avetisyan, G.; Schmidt, H.; Rathjen, F. Molecular Analysis of Sensory Axon Branching Unraveled a CGMPDependent Signaling Cascade. Int. J. Mol. Sci. 2018, 19, 1266. [CrossRef]

49. Davis, B.M.; Frank, E.; Johnson, F.A.; Scott, S.A. Development of Central Projections of Lumbosacral Sensory Neurons in the Chick. J. Comp. Neurol. 1989, 279, 556-566. [CrossRef]

50. Mauti, O.; Domanitskaya, E.; Andermatt, I.; Sadhu, R.; Stoeckli, E.T. Semaphorin6A Acts as a Gate Keeper between the Central and the Peripheral Nervous System. Neural Dev. 2007, 2, 28. [CrossRef]

51. Bron, R.; Vermeren, M.; Kokot, N.; Andrews, W.; Little, G.E.; Mitchell, K.J.; Cohen, J. Boundary Cap Cells Constrain Spinal Motor Neuron Somal Migration at Motor Exit Points by a Semaphorin-Plexin Mechanism. Neural Dev. 2007, 2, 21. [CrossRef]

52. Golding, J.P.; Cohen, J. Border Controls at the Mammalian Spinal Cord: Late-Surviving Neural Crest Boundary Cap Cells at Dorsal Root Entry Sites May Regulate Sensory Afferent Ingrowth and Entry Zone Morphogenesis. Mol. Cell. Neurosci. 1997, 9, 381-396. [CrossRef] [PubMed]

53. Chang, C.-H.; Zanini, M.; Shirvani, H.; Cheng, J.-S.; Yu, H.; Feng, C.-H.; Mercier, A.L.; Hung, S.-Y.; Forget, A.; Wang, C.-H.; et al. Atoh1 Controls Primary Cilia Formation to Allow for SHH-Triggered Granule Neuron Progenitor Proliferation. Dev. Cell 2019, 48, 184-199.e5. [CrossRef]

54. Kang, M.C.; Lee, J.-W.; Lee, T.H.; Subedi, L.; Wahedi, H.M.; Do, S.-G.; Shin, E.; Moon, E.-Y.; Kim, S.Y. UP256 Inhibits Hyperpigmentation by Tyrosine Expression/Dendrite Formation via Rho-Dependent Signaling and by Primary Cilium Formation in Melanocytes. Int. J. Mol. Sci. 2020, 21, 5341. [CrossRef]

55. Berbari, N.F.; Bishop, G.A.; Askwith, C.C.; Lewis, J.S.; Mykytyn, K. Hippocampal Neurons Possess Primary Cilia in Culture. J. Neurosci. Res. 2007, 85, 1095-1100. [CrossRef] [PubMed]

56. Kalil, K.; Dent, E.W. Branch Management: Mechanisms of Axon Branching in the Developing Vertebrate CNS. Nat. Rev. Neurosci. 2014, 15, 7-18. [CrossRef]

57. Miller, K.E.; Suter, D.M. An Integrated Cytoskeletal Model of Neurite Outgrowth. Front. Cell. Neurosci. 2018, 12, 447. [CrossRef]

58. Armijo-Weingart, L.; Gallo, G. It Takes a Village to Raise a Branch: Cellular Mechanisms of the Initiation of Axon Collateral Branches. Mol. Cell. Neurosci. 2017, 84, 36-47. [CrossRef]

59. Pinskey, J.M.; Franks, N.E.; McMellen, A.N.; Giger, R.J.; Allen, B.L. Neuropilin-1 Promotes Hedgehog Signaling through a Novel Cytoplasmic Motif. J. Biol. Chem. 2017, 292, 15192-15204. [CrossRef]

60. Choksi, S.P.; Lauter, G.; Swoboda, P.; Roy, S. Switching on Cilia: Transcriptional Networks Regulating Ciliogenesis. Development 2014, 141, 1427-1441. [CrossRef]

61. Thomas, J.; Morlé, L.; Soulavie, F.; Laurençon, A.; Sagnol, S.; Durand, B. Transcriptional Control of Genes Involved in Ciliogenesis: A First Step in Making Cilia. Biol. Cell 2010, 102, 499-513. [CrossRef] [PubMed] 
62. Oblinger, M.; Lasek, R. A Conditioning Lesion of the Peripheral Axons of Dorsal Root Ganglion Cells Accelerates Regeneration of Only Their Peripheral Axons. J. Neurosci. 1984, 4, 1736-1744. [CrossRef] [PubMed]

63. Zhang, Y.; Williams, P.R.; Jacobi, A.; Wang, C.; Goel, A.; Hirano, A.A.; Brecha, N.C.; Kerschensteiner, D.; He, Z. Elevating Growth Factor Responsiveness and Axon Regeneration by Modulating Presynaptic Inputs. Neuron 2019, 103, 39-51.e5. [CrossRef] [PubMed]

64. Andermatt, I.; Wilson, N.; Stoeckli, E.T. In Ovo Electroporation of miRNA-Based-Plasmids to Investigate Gene Function in the Developing Neural Tube. In Gene Function Analysis; Ochs, M.F., Ed.; Methods in Molecular Biology; Humana Press: Totowa, NJ, USA, 2014; Volume 1101, pp. 353-368. ISBN 978-1-62703-720-4.

65. Wilson, N.H.; Stoeckli, E.T. Cell Type Specific, Traceable Gene Silencing for Functional Gene Analysis during Vertebrate Neural Development. Nucleic Acids Res. 2011, 39, e133. [CrossRef] [PubMed]

66. Williams, R.M.; Senanayake, U.; Artibani, M.; Taylor, G.; Wells, D.; Ahmed, A.A.; Sauka-Spengler, T. Genome and Epigenome Engineering CRISPR Toolkit for in Vivo Modulation of Cis -Regulatory Interactions and Gene Expression in the Chicken Embryo. Development 2018, 145, dev160333. [CrossRef] [PubMed]

67. Gandhi, S.; Piacentino, M.L.; Vieceli, F.M.; Bronner, M.E. Optimization of CRISPR/Cas9 Genome Editing for Loss-of-Function in the Early Chick Embryo. Dev. Biol. 2017, 432, 86-97. [CrossRef] [PubMed]

68. Hamburger, V.; Hamilton, H.L. A Series of Normal Stages in the Development of the Chick Embryo. J. Morphol. 1951, 88, 49-92. [CrossRef]

69. Andermatt, I.; Wilson, N.H.; Bergmann, T.; Mauti, O.; Gesemann, M.; Sockanathan, S.; Stoeckli, E.T. Semaphorin 6B Acts as a Receptor in Post-Crossing Commissural Axon Guidance. Development 2014, 141, 3709-3720. [CrossRef]

70. Wilson, N.H.; Stoeckli, E.T. In Ovo Electroporation of MiRNA-Based Plasmids in the Developing Neural Tube and Assessment of Phenotypes by DiI Injection in Open-Book Preparations. JoVE 2012, 4384. [CrossRef]

71. Das, R.M.; Storey, K.G. Apical Abscission Alters Cell Polarity and Dismantles the Primary Cilium During Neurogenesis. Science 2014, 343, 200-204. [CrossRef]

72. Dumoulin, A.; Dagane, A.; Dittmar, G.; Rathjen, F.G. S-Palmitoylation Is Required for the Control of Growth Cone Morphology of DRG Neurons by CNP-Induced CGMP Signaling. Front. Mol. Neurosci. 2018, 11, 345. [CrossRef] [PubMed]

73. Schindelin, J.; Arganda-Carreras, I.; Frise, E.; Kaynig, V.; Longair, M.; Pietzsch, T.; Preibisch, S.; Rueden, C.; Saalfeld, S.; Schmid, B.; et al. Fiji: An Open-Source Platform for Biological-Image Analysis. Nat. Methods 2012, 9, 676-682. [CrossRef] [PubMed] 